\title{
Characterization of Hybrid Composite Made of False Banana Fiber and Sisal Fiber
}

\author{
Dawit Wami Negera, Bhaskaran. J, Idiris Ilmi, Ramesh Babu Nallamothu
}

\begin{abstract}
The importance of natural fiber reinforced composites is rapidly developing both in terms of engineering application and research field. The aim of this investigation is conducting an experiment to obtain the water absorption, physical and Mechanical properties of hybrid composite was fabricated from (False Banana Fiber) FBF and (Sisal Fiber) SF through general purpose (GP) resin-hardener mixture. The samples fabrication procedure was carried out by varying FBF and SF weight ratio to see its effect of mechanical and physical properties. Three samples (FBF: SF) i.e., 1:1 ratio, 3:1 ratio and 1:3 ratio with ply orientation as the reinforcement material. Then, tensile strength, compression strength, flexural strength water absorption percentage and density was conducted according to ISO and ASTM standards. The results show that the overall tensile strength shows a 1:3 ratio have shown $69 \mathrm{MPa}$ which are higher than 1:1 ratio and 3:1 ratio. 3:1 ratio. In a compression strength test also 12.30 MPa which was higher result is obtained from 3:1 ratio. For both flexural(bending) strength and water absorption (for ordinary tap water and rainwater) test $380 \mathrm{MPa}$ and $(2.64 \%$ and $3.07 \%)$ respectively resulted, which are relatively less than from 1:1 ratio and 3:1ratio.
\end{abstract}

Keywords: Experiment, flexural strength, GP resin, Hybrid composite, Volume fraction

\section{INTRODUCTION}

Increasing attention towards sustainable development and environment awareness forces researchers to explore more on the green biodegradable materials based on agricultural wastes [3]. The growing environmental concerns, global warming, waste management issues, dwindling fossil resources, and rising oil prices have resulted in increase in research for newer materials that are friendly to our health and environment. Green products are being increasingly promoted for sustainable development [18].

Revised Manuscript Received on December 30, 2019.

* Correspondence Author

Dawit Wami, Mechanical Engineering department, Assosa University, Assosa, Ethiopia. Email: d.wami@yahoo.com

Dr. Bhaskaran. J, Design and Manufacturing Engineering Department, Adama Science and Technology University, Adama, Ethiopia. Email: bhaskaranj@gmail.com

Idiris Ilmi, Mechanical Systems and Vehicle Engineering Department, Adama Science and Technology University, Adama, Ethiopia. Email: idirisilmi $1 @$ gmail.com

Dr. Ramesh Babu, Mechanical Systems and Vehicle Engineering Department, Adama Science and Technology University, Adama, Ethiopia. Email: rbnallamothu@gmail.com

(C) The Authors. Published by Blue Eyes Intelligence Engineering and Sciences Publication (BEIESP). This is an open access article under the CC BY-NC-ND license (http://creativecommons.org/licenses/by-nc-nd/4.0/)
A new trend in engineering research is to replace heavy metals with polymer material reinforced with natural fibers such as different plants, animal and wood fibers. Many researchers have focused to replace heavy metals by some materials with low density and high strength. Thus, the use of polymers in various applications has grown rapidly. Now a

day application of polymer-based products can be found from house hold utilities to space applications [12]. The sources of natural fibers are from plant, animal and minerals. Some examples of natural fibers are: banana, abaca, hemp, wood fiber, bamboo, cotton, coir, flax, jute, rice husks, straw wheat, coconut, coir, henequen, sisal, ramie, water pennywort, kapok, pineapple leaf fiber, grass reeds, oil palm empty fruit bunch, cotton, bagasse, alpaca, angora, bisdown, camelhair, chasmere, acetate, triacetate, art silk, asbestos, etc. [1], [13]. Fiber hybridization is a promising strategy to toughen composite materials. By combining two or more fiber types, these hybrid composites offer a better balance in mechanical properties than non-hybrid composites. Predicting their mechanical properties is challenging due to the synergistic effects between both fibers [19]. The criteria's needed in automotive industry during material selection are result of regulation and legislation with the environmental and safety and the other is the customers' requirements. To optimize and balance solution success full design only be possible this also resolve different factors that may conflicting [7]. The basic aim of developing a new material for automotive application is to enhance vehicle efficiency and fuel economy by reducing the dead weight of the vehicle. Moreover, their aesthetical appearance should be upgraded by researching materials for this application too. A number of researches have been demonstrated that composite materials are lightweight, fatigue resistant and easily molded to any shape, in other words, a seemingly attractive alternative to metallic materials. If the benefits of composite materials in terms of light weighting, durability, good aesthetical value, high specific energy absorption ability and ease of forming are to be exploited more widely by the automotive industry, then there is a need to identify the critical technical barriers that must be overcome [16]. Through weight reduction the fuel consumption may also be decreasing. By the $10 \%$ weight decreasing, the fuel consumption of a vehicle decreases by $7 \%$, what also means that reducing the weight by about $1 \mathrm{~kg}$ will measurably reduce the $\mathrm{CO}_{2}$ emissions. The car producers are trying to reduce the greenhouse gas by using new ultralight materials. The only one obstacle for using this kind of materials is their price, and that is the reason to develop new technologies a production process. The impact strength is an ability of the material structure to absorb the energy through a controlled way. 
The demands for car impact strength are: Deformable end section of the car, which preserve the integrity of the back-passenger space and protect the fuel tank, Right designed the side structure and the doors, Strength roof construction, that protect by the turnover and Properly designed interior space. Composite materials have great ability to absorb the energy. They are made up from layers that are absorbing the impact energy by the separating process. The ability of the energy absorbing is shown on the next figure. Applications of new materials as plastics or composites are allowing the constructors to design variously shapes of components. Modern car design is affecting the security, performance, aerodynamics, fuel consumption, production costs and many other important factors. Composite materials are also used for better look of exterior and interior parts such as seats, dashboards, bumpers, diffusor and so on. Nowadays there are many different studies and prototypes of full carbon car bodies [14].

Due to rise in demand of lightweight and more efficient vehicles and better mechanical performance of materials in automotive applications, different material combinations such as composites, plastic and light weight metals are implemented on different structural parts of vehicles. Applications of composite materials in automotive industries already include some structural parts, such as dashboard, roof, floor, front and back bumper, passenger safety cell, and door panels [10].

The main reason why composite materials are advanced in this decade includes its low density (which may lead to weight reduction of 10 to $30 \%$ ), good mechanical properties, favorable processing properties, favorable accident performance, high stability, favorable Eco-balance for part production, favorable Eco-balance during vehicle operation due to weight savings, occupational health benefits compared to synthetic fibers during production, price advantages both for the fibers and the applied technologies and etc.

Moreover, automotive and packaging industries are demanding a shift of their design from oil-derived polymers and mineral reinforcement materials to natural materials focusing the recyclability or biodegradability of "green", products at the end of life. Agricultural waste derived natural fibers can play a vital role in producing composites-based products and reducing environmental problems. Natural fibers are affordable, degradable, manageable, recyclable, and renewable [3].

The most important advantages of natural fibers relate to environmental issues: they are biodegradable and carbon positive, since they absorb more carbon dioxide than they produce [5], [11]. Other important advantages are shown in terms of specific material properties: using natural fibers in place of synthetic ones, it is possible to reduce the weight of a composite material by up to $40 \%$, and it is also possible to improve flexural strength, stiffness and ductility [6]. Natural fiber reinforced thermoplastic composites showed supremacy over conventional materials owing to ease of processing, fast production cycling and low tooling cost, thus making them most suitable materials for automobile and electrical industries [15]. In comparison with synthetic fibers, natural fibers are low in cost, low density, and have highly specific properties [17]. Weight reduction can be achieved primarily by the research of better material, design optimization and better manufacturing processes [17].

\section{METHODOLOGY}

\section{A. Dimension of Test specimens}

The appropriate Ethiopian Conformity Assessment Enterprise (ECAE) Testing material (ISO 6892-1) standards were followed while preparing the specimens for hybrid composite of FBF and SF for tensile test and their values are illustrated in Figure 1 and specimens for tensile strength test ASTM standards ASTM D - 638, for flexural (bending) strength test using ASTM D - 790 and compression strength test using ASTM standards ASTM D - 3410.
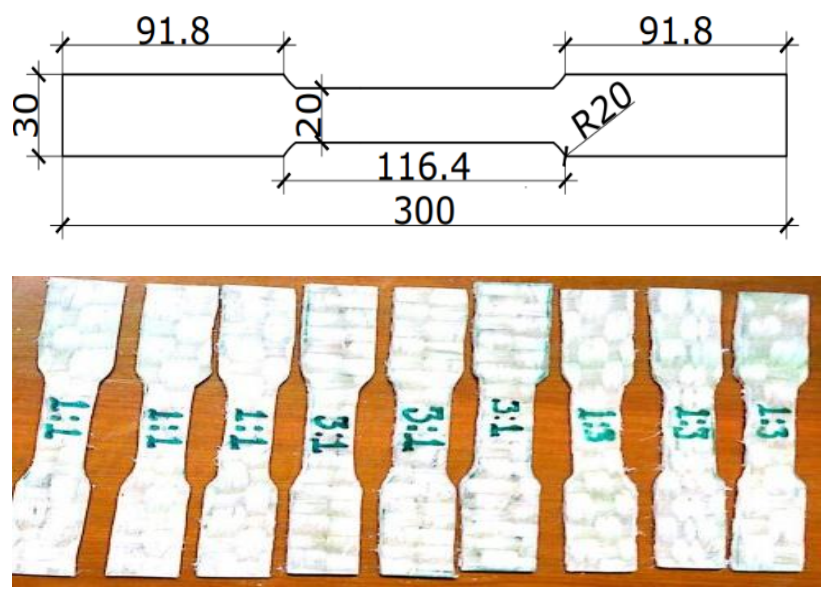

(a) Tensile Test Specimen
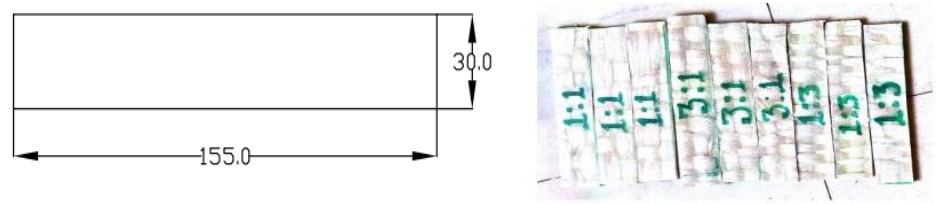

(b)
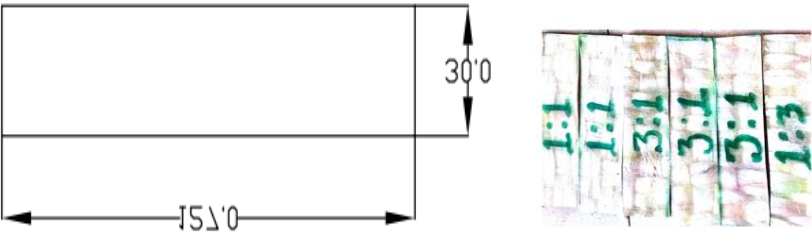

(c)

(b) Compression Test Specimen (c) Bending Test Specimen Fig. 1. Test specimen dimensions.

\section{Testing procedure of specimen}

The test procedure of sample was conducted by preparing specimen based on the kind of test conducted. The mechanical and physical properties test conducted in this study is indicated by Table 1 given below. 
Table- I: Tests and machine on which tests was conducted.

\begin{tabular}{|l|l|l|}
\hline No & Name of the Test & $\begin{array}{l}\text { Name of the } \\
\text { Machine/specification }\end{array}$ \\
\hline 1 & Tensile Strength & UTM $-2000 \mathrm{kN}$ \\
\hline 2 & Compression Strength & UTM $-100 \mathrm{kN}$ \\
\hline 3 & Flexural Strength & UTM $-100 \mathrm{kN}$ \\
\hline 4 & Density & Water immersion method \\
\hline 5 & Water Absorption & Water immersion method \\
\hline
\end{tabular}

A. TENSILE STRENGTH TEST
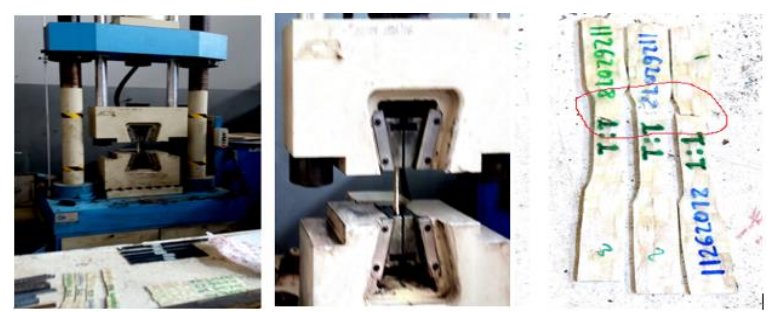

(C) After failure

Fig. 2. Tensile strength test.

\section{B. COMPRESSION STRENGTH TEST}

Fig. 3. Compression strength test
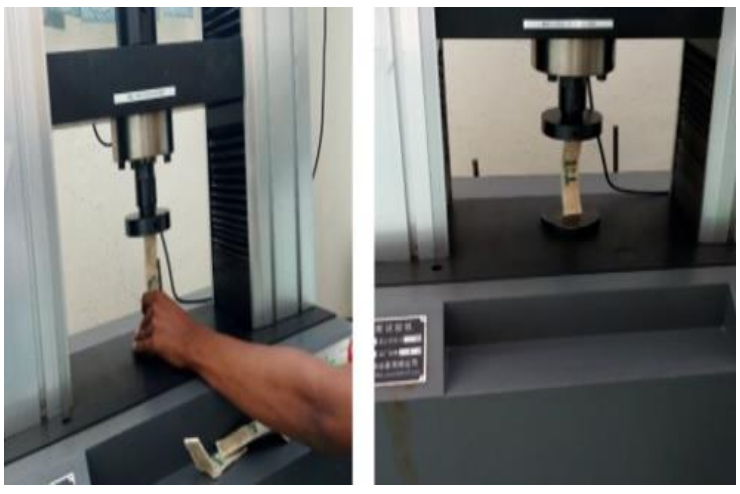

3. Flexural strength test

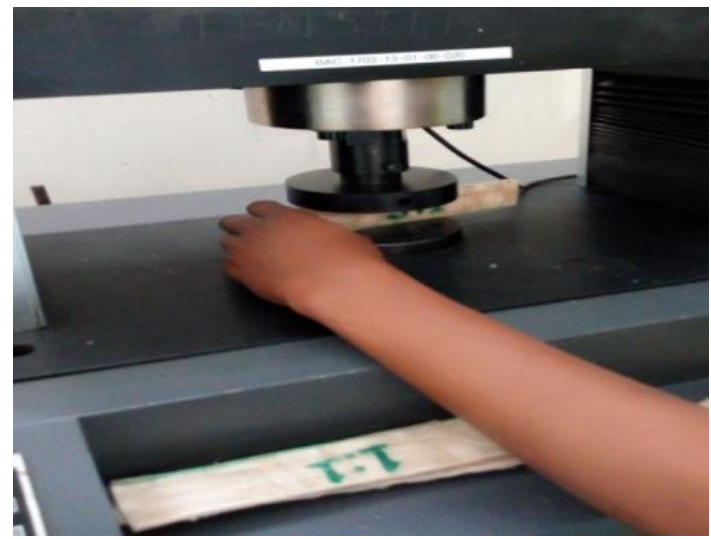

Fig. 4. Flexural (bending) strength test. (a) Spacemen placement (B) During specimen tauten

\section{Measurement of density}

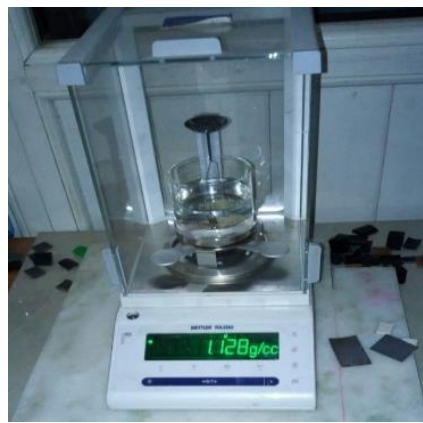

Fig. 5. Density measuring.

\section{Water Absorption}

According to literatures' source moisture absorption was conducted in accordance with ASTM D - 570-98. Single specimens of each composite are cut and their weights are taken as per their samples. All samples were immersed into water for 5 days. Then the specimen is removed from water and cleaned by dry materials and their weights are measured within 24 hrs. difference. The measurement was taken immediately after the specimens removed from immersed water, dried by dry materials and exposed to air. The specimen size prepared was $30 \mathrm{~mm} \times 30 \mathrm{~mm}$. The following equation was obtained from [12], [15].

\section{$\%$ Water Absorption}

$$
=\frac{\mathrm{W}_{\mathrm{t}}-W_{o}}{\mathrm{~W}_{\mathrm{o}}} \times 100 \text { OR } \frac{\mathrm{M}_{\mathrm{W}}-M_{a}}{\mathrm{M}_{\mathrm{a}}} \times 100
$$

Where : $\mathrm{W}_{\mathrm{t}}=$ Weight of Wet sample, $\mathrm{W}_{\mathrm{o}}=$ Weight of dry sample

$$
\mathrm{M}_{\mathrm{W}}=\text { Mass of Wet sample }, \mathrm{M}_{\mathrm{a}}=\text { Mass of dry sample }
$$
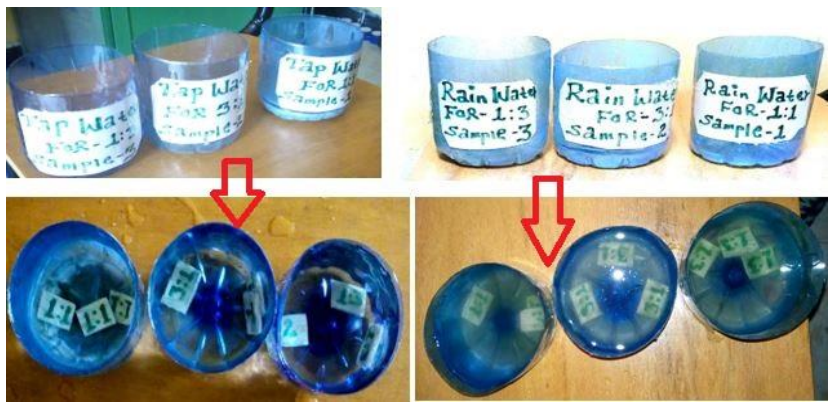

Fig. 6. Water absorption test.

\section{E. Mass Calculation}

From the density relationship the mass of the dashboard is calculated from the SOLID WORK 2017 software for both conventional dashboard and modified that made of metal sheet and composite material respectively.

Steps to analysis the mass of both materials from Solid Wok 2017 first select items (components or solid bodies) to be evaluated then mass property and then open option after that feed the steel metal sheet density and average density of hybrid composite material.

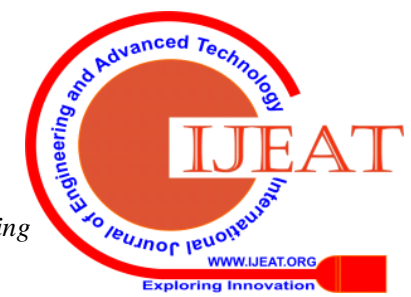


PEUGEOT model vehicles dashboard is steel metal sheet laminated by rubber, so let take the density of steel sheet metal for comparing with the hybrid composite of FBF and SF

Now, calculate the mass saved for the dashboard

Mass Saved $=$

Mass of convectional dashboard - Mass of composite material

$\%$ Mass Saved $=\frac{\text { Mass Saved }}{\text { Mass of convectional dashboard }} \times 100$

\section{RESULTS AND DISCUSSION}

\section{A. Analysis of Tensile strength}

The tensile strength test results are tabulated and presented in the Fig. 7. based on the hybrid composition of FBF and SF ratios with three trial specimens for each (FBF: SF) of 1:1 ratio,3:1 ratio and 1:3 ratio and average value for those specimens.

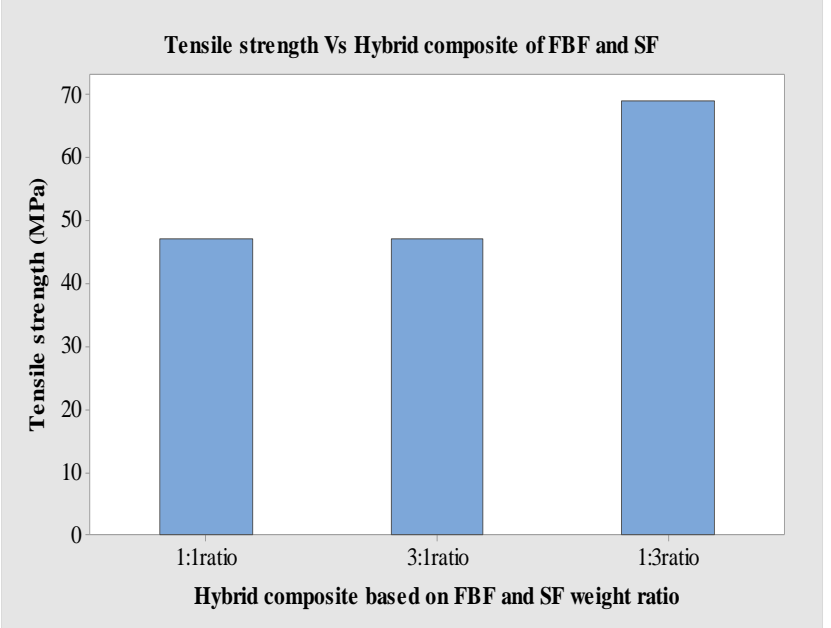

Fig. 7. Comparison tensile str with different weight fraction.

Based on fabricated composite average tensile stress value hybrid composite of FBF and SF with 1:3 ratio has higher tensile strength. Hybrid composite of FBF and SF with 1:1 ratio and 3:1 ratio has equal tensile strength. Shortly, from this study point of view, Hybrid composite of FBF and SF with 1:1 ratio and 3:1 ratio exhibit lower tensile strength.

\section{B. Analysis of compression strength}

Compression test results show that hybrid composite of FBF and SF with 3:1 ratio has higher compression strength. Hybrid composite of FBF and SF with 1:1 ratio exhibit relatively very lower compression strength. Hybrid composite of FBF and SF with 1:3 ratio exhibit approximately approach to the hybrid composite of FBF and SF with 3:1 ratio. From the study point, fabricated composite materials which has false banana fiber (FBF) has good compression strength relative to others. Maximum applied load, maximum deflection for three hybrid composites of FBF and SF with 1:1 ratio and 1:3 and 3:1 ratio with each ratio three trial sample specimens.

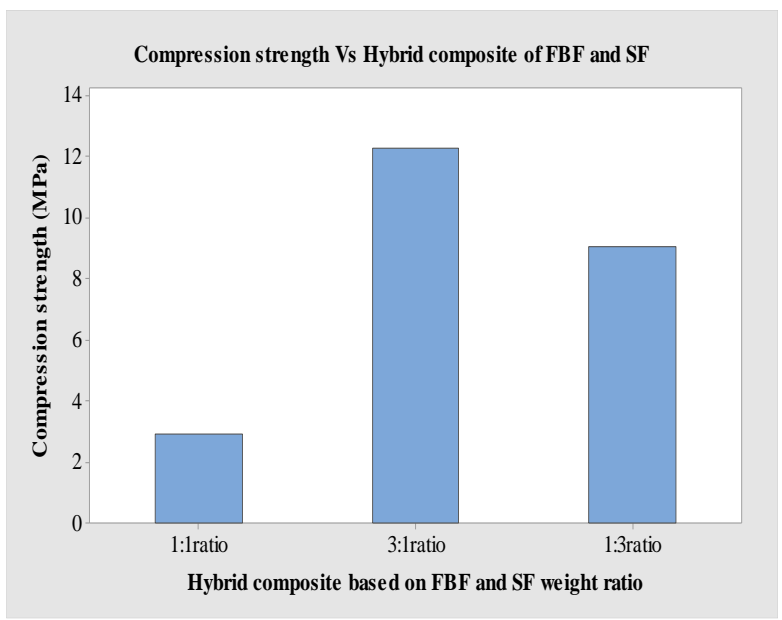

Fig. 8. Comparison of Compression strength with different weight fraction.

\section{Analysis of flexural (bending) strength}

The flexural test results are tabulated and present in Fig 9. Based on the maximum values of the three-hybrid composite of FBF and SF with each three trial specimens. The average flexural test results are presented graphically.

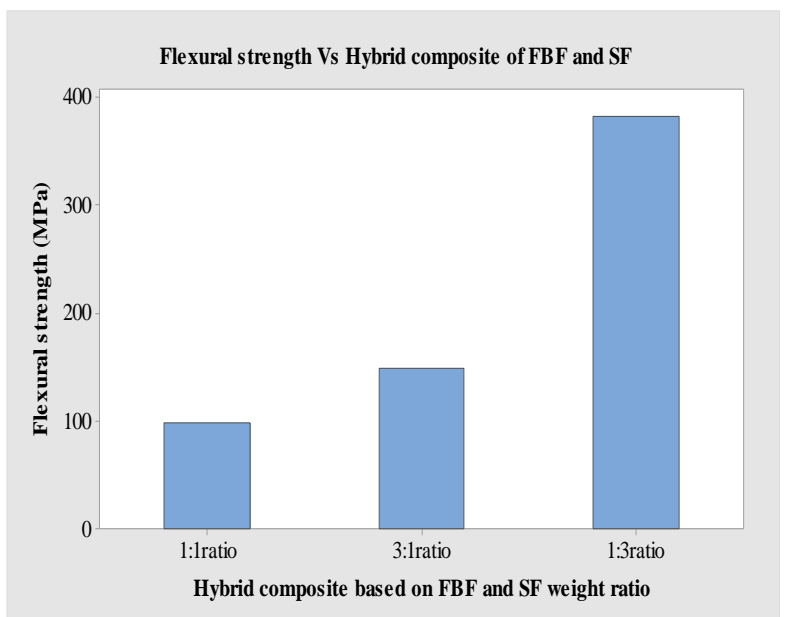

Fig. 9. Comparison of flexural (Bending) strength with deferent weight fraction.

Based on fabricated composite material average flexural (bending) strength value of hybrid composite of FBF and SF with 1:3 ratio is higher. It was clearly seen as the ratio of sisal fiber increase the flexural(bending) strength value of composite material also increase. Shortly, from this study point of view hybrid composite of FBF and SF with 1:1 ratio has relatively lower flexural (bending) strength average value and hybrid composite of FBF and SF with 3:1 ratio exhibit relatively moderate average value. The average value of hybrid composite of FBF and SF with 1:3 ratio exhibit two times more than 3:1 ratio.

\section{Water Absorption percentage}

The water absorption results for ordinary tap water and rain water are tabulated and presented in the Fig 10 based on the hybrid composition of FBF and SF ratios with three trial specimens for each ratio and average value for those specimens. 
Water absorption percentage of all hybrid composite FBF and SF average values for ordinary tap water and rain water was tabulated and analyzed individually in 5 days (120 hours). The comparison is done on average value of each samples.

\section{\% WA for tap water and rain water Vs Hybrid composite of FBF and SF}

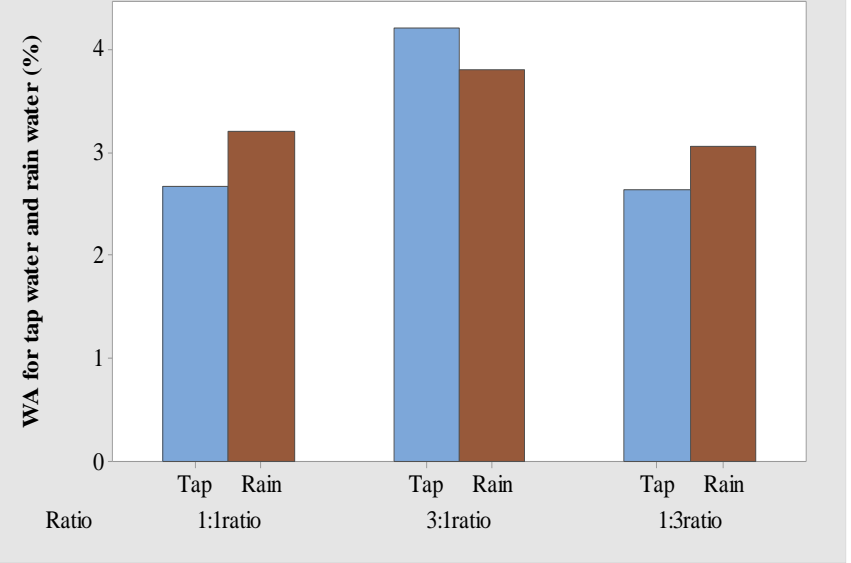

Fig. 10. Comparison \% water absorption with different weight fraction.

From the result point of view, for ordinary tap water, hybrid composite of FBF and SF with 3:1 ratio has very high-water absorption. Hybrid composite of FBF and SF with 1:3 ratio has less water absorption and hybrid composite of FBF and SF with 1:1 ratio relatively nearly the same value with 1:1 ratio.

For rain water, hybrid composite of FBF and SF with 3:1 ratio has very high-water absorption. Hybrid composite of FBF and SF with 1:3 ratio has less water absorption and hybrid composite of FBF and SF with 1:1 ratio has relatively moderate value.

It was clearly seen that, more water absorption is seen for rain water relative to ordinary tap water. This indicates that composite material absorbs more water, if the water is hard water (rain water). On both types of water hybrid composite of FBF and SF with 3:1 ratio has more water absorption then $1: 1$ ratio the least water absorption is seen for $1: 3$ ratio.

Higher water absorption percentage is not recommended for automotive body and other industry applications.

\section{E. Density Analysis}

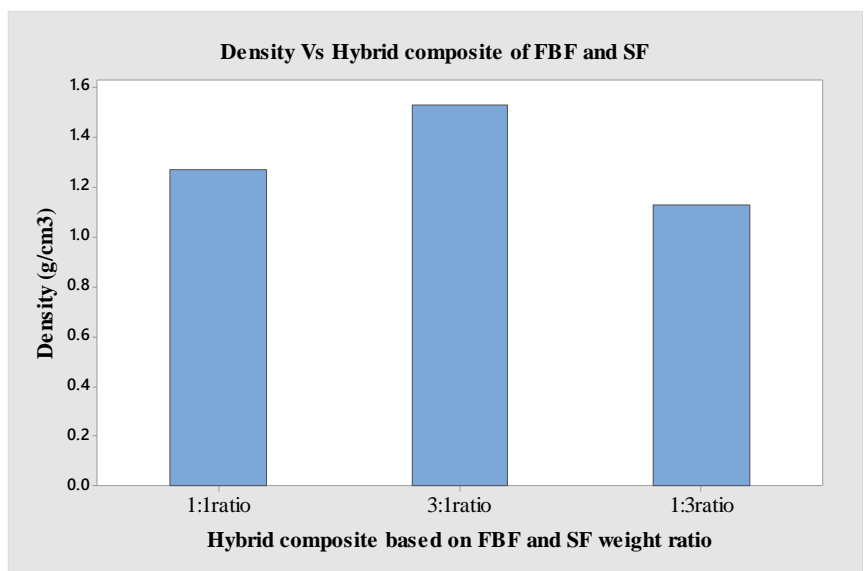

Fig. 11. Comparison of density with different weight fraction.
Density of hybrid composite of FBF and SF 3:1 ratio is more and hybrid composite of FBF and SF with 1:3 ratio has less density than the other and hybrid composite of FBF and SF with 1:1 ratio has moderate density relative to others.

The main objective of the study of density is reducing the weight that means as density decrease mass also decrease.

Density of automotive body component, increasing false banana fiber ratio increases. So, using false banana fiber relative to sisal fiber in composite material is not recommended.

\section{F. Mass reduction in percentage}

The mass of both conventional (steel metal sheet laminated by rubber) vehicle dashboard and hybrid composite material of FBF and SF vehicle dashboard results from Solid Work 2017 are tabulated in Table 4.6.

In Fig 12. shows percentage mass reduction for hybrid composite material of FBF and SF vehicle dashboard are computed graphically.

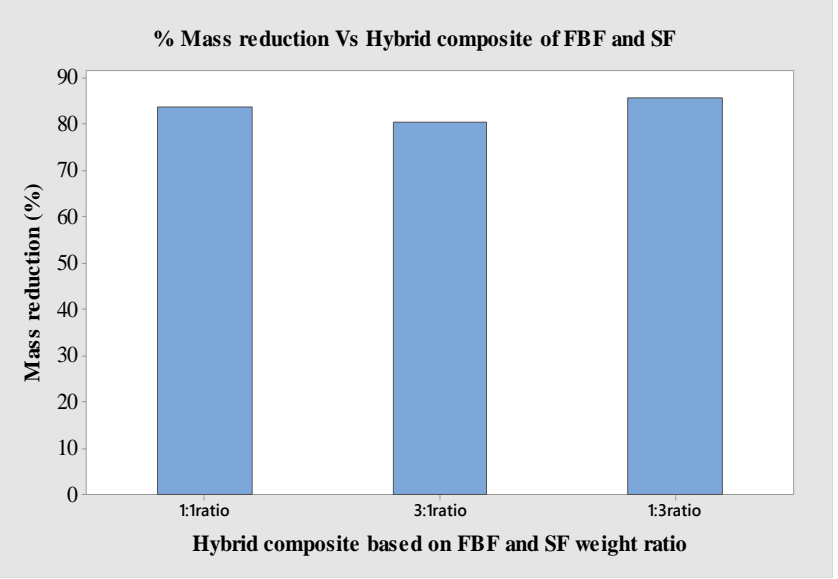

Fig. 12. Comparison of mass reduction with different weight fraction.

Percentage mass reduction of hybrid composite of FBF and SF 1:3 ratio is more and hybrid composite of FBF and SF with 3:1 ratio has less than the other and hybrid composite of FBF and SF with 1:1 ratio has moderate percentage mass reduction relative to others. This means hybrid composite of FBF and SF 1:3 ratio can save more mass than others next to hybrid composite of FBF and SF 1:3 ratio , the best mass reduction are seen on composite of FBF and SF 1:1 ratio and hybrid composite of $\mathrm{FBF}$ and $\mathrm{SF}$ 3:1 ratio the least that can save the mass relative to other.

The main goal of the study of percentage mass reduction is reducing the mass of automobile body component (vehicle dashboard). As, clearly shown from Table 4.6 as density decrease Percentage mass reduction of hybrid composite of FBF and SF and vice versa. Percentage mass reduction of hybrid composite of FBF and SF of automotive body component (vehicle dashboard) with less Percentage mass reduction of hybrid composite of FBF and SF is not recommended. 


\section{Characterization of Hybrid Composite Made of False Banana Fiber and Sisal Fiber}

Table- II: Density, mass, mass saved in gram and percentage.

\begin{tabular}{|c|c|c|c|c|c|}
\hline Materials & $\begin{array}{c}\text { Density } \\
\left(\mathrm{g} / \mathrm{cm}^{3}\right)\end{array}$ & $\begin{array}{c}\text { Mass } \\
(\mathrm{g})\end{array}$ & $\begin{array}{c}\text { Volume } \\
\left(\mathrm{cm}^{3}\right)\end{array}$ & $\begin{array}{c}\text { Mass saved } \\
(\mathrm{g})\end{array}$ & $\begin{array}{c}\text { Mass saved } \\
(\%)\end{array}$ \\
\hline Steel Sheet Metal & 7.800 & 26890587.84 & 3447.511 & - & - \\
\hline $\begin{array}{c}\text { Composite Material } \\
(1: 1 \text { ratio) }\end{array}$ & 1.270 & 4378339.302 & 3447.511 & $22,512,248.538$ & $\mathbf{8 3 . 7 1 8}$ \\
\hline $\begin{array}{c}\text { Composite Material } \\
\text { (3:1 ratio) }\end{array}$ & 1.530 & 5274692.230 & 3447.511 & $21,615,895.610$ & $\mathbf{8 0 . 3 8 5}$ \\
\hline $\begin{array}{c}\text { Composite Material } \\
(1: 3 \text { ratio) }\end{array}$ & 1.128 & 3888792.703 & 3447.511 & 23001795.137 & $\mathbf{8 5 . 5 3 8}$ \\
\hline
\end{tabular}

\section{CONCLUSION}

Based on the tensile, compression, bending, density and water absorption properties experiment data results including material preparations in this thesis, the following conclusions are drawn;

- Hybrid composite of FBF and SF with 1:3 ratio exhibits excellent tensile strength. In this study, as hybrid composite filled by more sisal fiber by the Wight of three hand shows maximum value of tensile strength. But the sisal fiber filled by one hand the tensile strength result of the composite shows equal value. The maximum observed value of tensile strength was at 1:3 ratio which has average value of $69 \mathrm{MPa}$. Generally, a composite which filled by more ratio of sisal fibers have higher tensile strength but the composite that has equal ratio of FBF and SF and one to three ratios of FBF and SF has equal values of tensile strength both of them recorded average value of $47 \mathrm{MPa}$.

- The compression strength result indicates that hybrid composite of FBF and SF 3:1 ratio has the highest value than other hybrid composite of FBF and SF ratios with average harness value of $12.30 \mathrm{MPa}$.

- Results shows that the flexural (bending strength) of hybrid composite of FBF and SF with 1:3 ratio has highest value than other hybrid composite of FBF and SF ratios with average value of $380.9 \mathrm{MPa}$ which is two times greater than hybrid composite of FBF and SF with 3:1 ratio and three times greater than hybrid composite of FBF and SF 1:1 ratio. This indicates that more sisal fiber in hybrid composite of FBF and SF to get a material which cannot be simply flexure.

- water absorption percentage also takes place in two types of water. The first one is by ordinary tap water, in this type of water hybrid composite of FBF and SF with 3:1 ratio absorb more water relative to other ratios, this hybrid composite absorbs $4.21 \%$. Hybrid composite of FBF and SF with 1:1 ratio and 1:3 ratio absorb relatively the same amount of water absorb,2.68 \% and $2.64 \%$ respectively.

- For the second type of water which is rain water again hybrid composite of FBF and SF with 3:1 ratio recorded more water absorption up to $3.80 \%$ and hybrid composite of FBF and SF with 1:1 ratio follow the 3:1 ratio by 3.21 $\%$ result. The least rain water absorption seen for hybrid composite of 1:3 ratio.

- For both types of water, more water absorption is seen on hybrid composite of FBF and SF with 3:1 ratio and followed by 1:1 ratio and the list water absorption seen on $1: 3$ result. In this case, for water absorption percentage as the list number is more preferable. So, hybrid composite of FBF and SF with 1:3 is preferable. from those test results, a hybrid composite of FBF and SF with 3:1 ratio has more water absorption for both types of water so, a composite material which has more ratio of false banana fiber absorbs more water.

- For a vehicle body parts which are mostly expose to rain, it is not recommended to use much ratio of false banana fiber as reinforcing material for composite material.

- Results shows for density analysis, hybrid composite of FBF and SF with 3:1ratio has relatively higher density with $1.530 \mathrm{~g} / \mathrm{cm}^{3}$ value and hybrid composite of FBF and SF with $1: 1$ ratio follow by $1.27 \mathrm{~g} / \mathrm{cm}^{3}$ value the least density is shown on hybrid composite of FBF and SF with $1: 3$ ratio.

- In this case, for density analysis results as the list number is more preferable because density is directly proportional with mass, as the value of density decrease the mass also decrease vice versa. So, one of the aims of this paper is to minimize the mass of vehicle dashboard in this case the least density of hybrid composite of FBF and SF with 1:3 ratio is preferable.

\section{REFERENCES}

1. Arpitha, G. R., and Yogesha, B., “An overview on mechanical property evaluation of natural fiber reinforced polymers". Materials today: Proceedings, 4(2), 2755-2760, 2017.

2. Bakri, "Processing and characterization of Banana Fiber/Epoxy Composites: Effect of Alkaline Treatment" Materials Today: Proceedings, 4(2), 2871-2878, 2017.

3. Bhatnagar, "A Review on Composition and Properties of Banana Fibers. International Journal of Scientific and Engineering Research, Volume 6(Issue 5), 49-52, 2015.

4. Bogoeva-Gaceva, G., (2007). Natural fiber eco-composites. Polymer composites, 28(1), 98-107.

5. De Paola, S., Minak, "Green Composites. A Review of state of Art in Proceedings of 30th Dambai Adria Symposium on Advanced Mechanics Croation Society, 25-28, 2013.

6. Elaheh, G., "Materials in Automotive Application, State of the Art and Prospects". 2018.

7. Enrico, Joe Carruthers, "The future use of structural composite materials in the automotive industry, International Journal of vehicle design". 2007.

8. Ermias, GK., "Implementation of composite and plastics materials for vehicle light weight”, PH. D Thesis, (p 44-74), 2012.

9. Esmael, A., "Experimental Analysis of E-Glass /Epoxy \& E-Glass /polyester Composites for Auto Body Panel, AIJRSTEM - 2015 (pp 377-383), 2015. 
10. Fragassa, C., "Marine Applications of Natural Fibre-Reinforced Composites: Manufacturing Case Study. In Advances in Applications of Industrial Biomaterials Springer (pp. 21-47), 2017.

11. Haldar, P., Modak, N., "Comparative Evaluation of Mechanical Properties of Sisal-Epoxy Composites with and without Addition of Aluminium Powder,Materials" Today: Proceedings, 4(2), 3397-3406, 2017.

12. Mehamud, I., Raj., "Fabrication and Mechanical Property Evaluation of Ethiopia Banana Fiber Reinforced Polymer Composites". Science domain international, 1-10, 2016.

13. Michal, D. and Stefan, K., "Composite Materials Application in Car Production", 2014.

14. Paul, S.A., Boudenne, "Effect of fiber loading and chemical treatments on thermophysical properties of banana fiber/polypropylene commingled composite materials., (pp 1582-1588), 2008

15. R.Badrinath and T.Senthilvelan "Comparative investigation on Mechanical properties of banana and sisal reinforced polymer based on composite' Procedia Materials Science 2263 - 2272, 2014.

16. Sandeep, B. and Rupa, S.,"Automotive Door Design and Structural Optimization of Front Door for Commercial Vehicle with ULSAB Concept for Cost and Weight Reduction' Global Journal of Researches in Engineering (Automotive Engineering); Volume 12 (Issue 2) Version 1.0, 2012.

17. Satyanarayana, K. G., Guimarães, "Studies on lignocellulosic fibers of Brazil. Part I: Source, production, morphology, properties and applications, Composites Part A: Applied Science and Manufacturing, 38(7), 1694-1709, 2007.

18. Singh, J. I. P., Dhawan, V., "Study of Effect of Surface Treatment on Mechanical Properties of Natural Fiber Reinforced Composites. Materials Today: Proceedings, 4(2), 2793-2799, 2017.

19. Yentl Swolfs, Larissa, "Fiber hybridization in polymer composites, a review. Composites Part A: Applied Science and Manufacturing 67 (2014) p. 181-200, 2014.

\section{AUTHORS PROFILE}

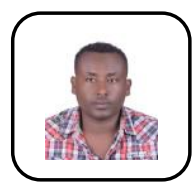

Dawit Wami Negera, working as Lecturer at the Department of Mechanical Engineering in Assosa University, Assosa, Ethiopia. He pursued BSc. in Mechanical Engineering from Arba Minch University, Arba Minch, Ethiopia, and MSc. from Adama Science and Technology University, Adama, Ethiopia.

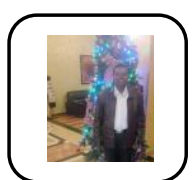

Dr. Bhaskaran. J, working as Asst Professor at the Department of Design and Manufacturing Engineering in Adama Science and Technology University, Adama, Ethiopia.

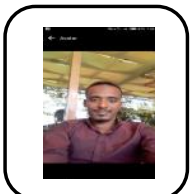

Idiris Ilmi, working as Lecturer at the Department of Automotive Engineering in Adama Science and Technology University, Adama, Ethiopia. He pursued MSc. in Automotive Engineering from Adama Science and Technology University, Adama, Ethiopia.

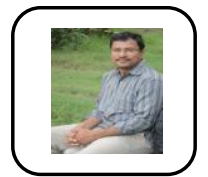

Dr. Ramesh Babu Nallamothu, working as Associate Professor in the Mechanical systems and vehicle Engineering Department, Adama Science and Technology University, Adama, Ethiopia. 